\title{
Factors Influencing the Intention of MSM to Use the PrEP Intelligent Reminder System
}

\author{
Yingjie $\mathrm{Ma}$ (D) \\ Xiaoni Zhong (D) \\ Bing Lin \\ Wei He
}

Department of Epidemiology and Health Statistics, School of Public Health and Management, Chongqing Medical University, Chongqing, People's Republic of China
Correspondence: Xiaoni Zhong Department of Epidemiology and Health Statistics, School of Public Health and Management, Chongqing Medical University, I Yixue Road, Chongqing, 4000 I6, People's Republic of China Tel +86/3308368059

Email zhongxiaoni@cqmu.edu.cn
Purpose: Low adherence to medication is an important reason why pre-exposure prophylaxis (PrEP) is not effective at reducing the rate of new human immunodeficiency virus (HIV) infections among men who have sex with men (MSM). The intelligent reminder system (IRS) has been designed to improve user compliance, but the intention of MSM to use the IRS remains unclear. This study establishes a theoretical model to analyze the factors influencing their intention to use the IRS.

Patients and Methods: Non-probability sampling was used to recruit MSM volunteers in Chongqing and Sichuan, China, and the data were collected from MSM who had used the IRS. A model based on the unified theory of acceptance and use of technology (UTAUT) was established for the data through a structural equation model, and the perceived privacy risk was considered to explore the subjects' behavior intention.

Results: A total of 111 volunteers who had used the IRS filled out a questionnaire. Social influence had the greatest impact on behavior intention $(\beta=0.360, \mathrm{P}<0.001)$, followed by performance expectancy $(\beta=0.331, \mathrm{P}<0.001)$, and perceived privacy risk had a negative impact on behavior intention $(\beta=-0.151, P=0.040)$. In addition, social influence had an indirect effect on behavior intention $(\beta=0.182, \mathrm{P}=0.003)$ and performance expectancy played a mediating role in this indirect effect.

Conclusion: Developments in the IRS are required to improve its usefulness and adequately explain its role when recommending it to MSM. It is also important to improve the system's ability to protect user privacy. Clinical evidence for the effectiveness of the IRS is conducive to its widespread use.

Keywords: AIDS, men who have sex with men, behavior intention, medication reminder, structural equation model

\section{Introduction}

Acquired immunodeficiency syndrome (AIDS) is a major public health problem. Around 36.9 million people were infected with the human immunodeficiency virus (HIV) worldwide at the end of 2017. ${ }^{1}$ As the largest developing country in the world, China has a particularly prominent AIDS problem. From 2004 to 2016, the number of HIV/AIDS cases in China rose from 0.2349 to 3.9898 per 100,000 people, and the number of AIDS-related deaths rose from 0.0570 to 1.0342 per 100 AIDS patients. The number of new HIV infections rose from 1.0199 to 6.4416 per 100,000 people in the same period, indicating that the situation in China is worsening. ${ }^{2}$ From January to July, 2018, there was a sudden increase in the number of new HIV infections in China, reaching 91,301 cases. ${ }^{3}$ Key relevant groups and their sexual partners accounted for a large portion of these cases, 
especially among men who have sex with men (MSM). The increasing trend of HIV transmission owing to homosexual activities is serious, and the rate of HIV infection of MSM is 200 times that of the general population. Between 2006 and 2015, 120,371 cases of AIDS were identified among MSM in China, and the number of new self-reported HIV cases among MSM increased from 487 to more than $30,000 .^{4}$ Although China has stepped up efforts to control the spread of the virus, systematic evaluation has shown that the rate of HIV testing among China's MSM is still very low. ${ }^{5}$ Low HIV testing rates result in the continued transmission of HIV among MSM. According to one report, male homosexual sex has become the leading cause of new HIV infections in the United States, accounting for $67 \%$ of the total. ${ }^{6}$ China's AIDS epidemic is approaching the scale of that of the United States, ${ }^{7}$ and cases of are increasingly becoming concentrated among MSM. ${ }^{4,7,8}$ MSM in southwest China have the highest HIV infection rate, where this has exceeded $10 \%$ in Sichuan and Chongqing. ${ }^{9}$

Although no drug or treatment can cure AIDS, HIV is preventable, and it is particularly important to take preventive measures to reduce its spread. Pre-exposure prophylaxis (PrEP) is the administration of antiretroviral (ARV) drugs to reduce the risk of HIV infection through sexual transmission in HIV-negative people. ${ }^{10}$ Two regimens are commonly used in clinical trials: (1) $300 \mathrm{mg}$ of tenofovir disoproxil fumarate (TDF), orally, and once daily; and (2) $300 \mathrm{mg}$ of tenofovir disoproxil fumarate (TDF) and $200 \mathrm{mg}$ of emtricitabine (FTC), orally, and once a day. Among MSM who are not infected by HIV, the efficacy and safety of long-term use of PrEP to prevent new HIV infection has been confirmed. ${ }^{10-12}$ The US Centers for Disease Control and Prevention found that the use of PrEP can reduce the rate of HIV infection in high-risk individuals by more than $90 \% .{ }^{13}$ In 2015 , the WHO officially included PrEP in its guidelines for preventing HIV infection in people who engage in high-risk sexual behaviors, indicating that PrEP is now a recognized means of preventing HIV infection. ${ }^{14}$ To reduce the number of new HIV infections by $90 \%$ within 10 years and end the HIV epidemic, it is vital to increase the use of PrEP. ${ }^{6}$ We conducted a nearly 13-year study (2008 to 2021) on the use of PrEP among MSM in Chongqing and Sichuan, during which we provided PrEP to subjects free of charge. However, the effectiveness of PrEP is related to whether high-risk individuals take their medication on time.
Improve their compliance with PrEP is thus worth investigating.

PrEP cannot adequately prevent HIV infection in MSM with low adherence. To solve the problems encountered in medication compliance, such as forgetting to take medicine, taking too much medicine, and taking the wrong medicine, ${ }^{15}$ a large number of intelligent reminder systems (IRS) and intelligent medicine boxes have been developed in recent years. The IRS is an intelligent system designed to remind people to take their medicine. ${ }^{16}$ Some studies have explored the use of reminders to improve PrEP adherence in the United States, ${ }^{17,18}$ but doing so by using the short message service (SMS) and apps is expensive, and cannot guarantee user privacy. A study has also shown that MSM tend to protect their privacy by not using devices that can compromise their personal information. ${ }^{19}$ Therefore, it is important to establish a system designed for MSM. IRS-related research is still rare in China, however. MSM are often afraid of being exposed, stigmatized, and discriminated against, ${ }^{20-22}$ especially in China. ${ }^{23,24}$ In traditional Chinese culture, homosexuality is considered a disgrace. ${ }^{25}$ In light of this, we subjected the manner in which the IRS sends reminders to users and its interface to privacy processing so that outsiders who accidentally see the content of the IRS cannot recognize its meaning, and anonymized the collected data to reduce the risk of exposing user privacy. We establish this system based on WeChat, a popular social media network in China. However, the willingness of MSM to use the IRS remains unknown, and its success depends on its acceptance among them.

The technology acceptance model (TAM) and the unified theory of acceptance and use of technology (UTAUT) can be used to examine people's willingness to use a new system. The UTAUT has been developed on the basis of the TAM, and expands the factors affecting people's willingness to use. The UTAUT has greater explanatory power with regard to the acceptance of technologies than the TAM. $^{26}$ This study analyzes the willingness of MSM to use the IRS through the UTAUT, provides suggestions for the production and improvement of such products, and proposes measure to improve the adherence to $\mathrm{PrEP}$ among MSM.

\section{Materials and Methods}

Theoretical Framework and Hypotheses

The UTAUT has been widely used in smart medicine, and many researchers have expanded the basic UTAUT. Hoque 
et al added anxiety regarding technology and resistance to change to it to study the main factors influencing the intention of the elderly to use mobile health services. ${ }^{27}$ In a study on people's intention to use wearable medical devices, Wang et al combined the task-technology fit with the UTAUT and claimed that it positively affects user intention. ${ }^{28}$ Zhang et al claimed that the perceived threat of a disease is the main factor influencing diabetic patients' intention of using diabetes management apps, and the risk of exposure of privacy is the factor influencing actual use of diabetes management apps. ${ }^{29}$ By using past work as well as the characteristics of MSM, this study adds the dimension of perceived privacy risk to the UTAUT to explore the factors influencing the use of IRS by MSM. The proposed model is shown in Figure 1.

In this study, performance expectancy refers to the degrees of improvement in medication compliance and reduction in HIV infection among MSM individuals after using the IRS. In general, we think that the higher the performance expectancy of a new system is, the more willing are people to use it. Performance expectancy is the most important factor affecting their intention to use, because of which we pose hypothesis 1 :

H1: Performance expectancy positively affects the intention of MSM to use the IRS.

Effort expectancy refers to the difficulty encountered by MSM to learn to operate the IRS. In general, we believe that the easier a new system is to learn and use, the more willing are people to use it. Therefore, we establish hypothesis 2:

H2: Effort expectancy positively affects the willingness of MSM to use the IRS.

Social influence refers to the support of people or doctors who are closely related to MSM in the context of their use of the IRS. In general, we believe that the higher the support provided by the users' relatives and friends is for using a new system, the more willing are the users are to use this system. Therefore, hypothesis 3 is established:

H3: Social influence can positively affect the intention of MSM to use the IRS.

In a study of web-based interactive self-management techniques, social influence was found to indirectly affect behavior intention through performance expectancy. ${ }^{30}$ In general, doctors' opinions often play an important role in forming their patients opinions, and the system recommended by them is considered useful. Therefore, the performance expectancy of MSM pertaining to the IRS may be affected by doctors' opinions. Therefore, hypothesis 4 is established:

H4: Social influence can positively affect the performance expectancy of MSM with regard to the IRS.

Facilitating conditions refer to whether MSM have the necessary materials, such as a mobile phone, WeChat, and mobile data, to use the IRS. Because the IRS reminds users to take medicine through WeChat, the materials

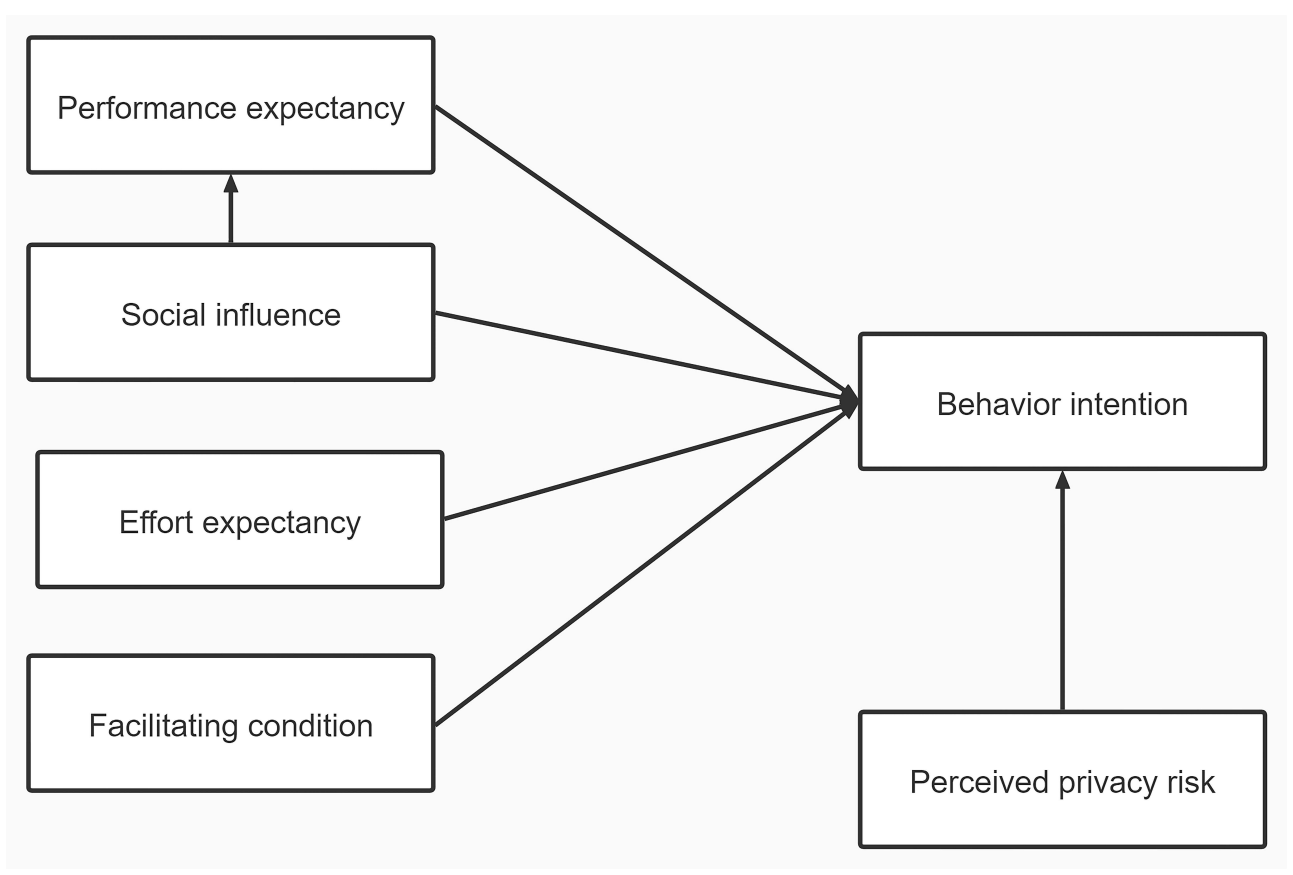

Figure I Research model. 
required as facilitating conditions are the ones described above. In general, we believe that the greater the lack of materials is to use a new system, the less often will they use the new system. Therefore, hypothesis 5 is established:

H5: Facilitating conditions can positively affect the intention of MSM to use the IRS.

As MSM are often afraid of their privacy being exposed, stigmatized, and discriminated, their intention to use the IRS is affected. In general, we believe that the greater the risk of privacy leakage is, the less willing are MSM to use a new system. Hypothesis 6 is thus posed:
H6: Perceived privacy risk negatively affects the intention of MSM to use the IRS.

\section{Data Collection}

The data were taken from "The study on improving the compliance of pre-exposure prophylaxis in MSM based on intelligent reminder system to reduce new HIV infections," initiated by the Ministry of Science and Technology of China (2012ZX10001-007). In this study, non-probability sampling was used in Chongqing and Sichuan in the southwest of China, and MSM volunteers

\begin{tabular}{|c|c|}
\hline Construct & Items \\
\hline \multicolumn{2}{|l|}{$\begin{array}{c}\text { Performance } \\
\text { expectancy }\end{array}$} \\
\hline PE1 & The intelligent reminder system can remind me to take my medication on time. \\
\hline PE2 & $\begin{array}{l}\text { The intelligent reminder system can better teach me the knowledge of AIDS prevention (if the } \\
\text { knowledge of AIDS prevention is provided). }\end{array}$ \\
\hline \multicolumn{2}{|l|}{ Effort expectancy } \\
\hline EE1 & It's easy to learn how to use the intelligent reminder system. \\
\hline EE2 & It's easy to actually use the intelligent reminder system. \\
\hline \multicolumn{2}{|l|}{ Social influence } \\
\hline SI1 & Doctors suggest me using the intelligent reminder system and I agree with the them. \\
\hline $\mathrm{SI} 2$ & $\begin{array}{c}\text { People close to me think I should use an intelligent reminder system, and I agree with } \\
\text { them. }\end{array}$ \\
\hline \multicolumn{2}{|l|}{ Facilitating condition } \\
\hline FC1 & $\begin{array}{l}\text { I have the resources required to use the intelligent reminder system (such as network, } \\
\text { mobile phone, WeChat). }\end{array}$ \\
\hline FC2 & I have the knowledge of using mobile phone, network and WeChat. \\
\hline FC3 & When I have trouble using the intelligent reminder system, I can get help from others. \\
\hline \multicolumn{2}{|l|}{$\begin{array}{l}\text { Perceived privacy } \\
\text { risk }\end{array}$} \\
\hline PPR1 & $\begin{array}{l}\text { I am worried about that my information will be leaked if I use the intelligent reminder } \\
\text { system. }\end{array}$ \\
\hline PPR2 & $\begin{array}{l}\text { I am concerned that my information might be used for other purposes if I use the } \\
\text { intelligent reminder system. }\end{array}$ \\
\hline \multicolumn{2}{|l|}{ Behavior intention } \\
\hline $\mathrm{Bl} 1$ & I would like to use or continue to use the intelligent reminder system. \\
\hline
\end{tabular}

Figure 2 Questionnaire. 
(gay or bisexual) were recruited by means of peer introduction, gay working groups, and gay websites by cooperating with non-government organizations (NGOs), publishing information on gay websites, and the "snowball" method. The MSM volunteers were randomly divided into two groups: the IRS group and the non-IRS group. In the informed consent, we asked MSM in the IRS group to take PrEP through the IRS, to which they agreed. The inclusion and exclusion criteria were strictly followed.

Inclusion criteria: (1) men who have sex with men, aged 18-65; (2) HIV negative; (3) frequency of sexual intercourse once every 2 weeks or more; (4) intercourse with one or more male sexual partners a month before the trial; (5) willingness to use research medication and IRS under the guidance and adhere to follow-up arrangements.

Exclusion criteria: (1) a positive HIV antibody test result at the time of screening; (2) HBsAg (hepatitis B surface antigen) or anti-HBc (hepatitis B core antibody) positive; (3) having a serious illness that the investigator believed might have affected the intervention, follow-up, or evaluation of the volunteers; (4) having received other study medications three months before the screening; (5) inability or unwillingness to provide informed consent, or inability to comply with test requirements.

Inclusion criteria for re-screening: HIV negative after taking the drug for one month.

The subjects of this study were MSM from the IRS group. After three months of using the IRS, a follow-up was conducted using a questionnaire. All questions in the questionnaire were set from previous studies on the acceptance of health information technology, and some items were deleted or replaced according to the research background to adapt it to this research. This ensured good surface validity, content validity, and structural validity (see Figure 2). All items were measured on a five-point Likert scale, with " 1 " representing "strongly disagree" and " 5 " representing "strongly agree." The questionnaire was filled out by the MSM, and a total of 111 filled-out questionnaires were collected.

\section{Data Analysis}

The demographic characteristics of MSM were analyzed by using the SAS9.4 software (Version 9.4. Raleigh, North Carolina: SAS Corp;2021). AMOS26.0 (Version 26.0. Armonk, NY: IBM Corp; 2021) was used to evaluate the reliability of the construct and the structural model. Reliability was measured by Cronbach's alpha and composite reliability, both of which needed to be greater than $0.70 .{ }^{31}$ We measured the validity of convergence based on the average variance extracted (AVE), and a value higher than 0.50 indicated that the construct had good convergence. The discriminant validity was acceptable if the correlation coefficient between structures was less than the square-root of the corresponding structure. The model fit was generally considered acceptable if $\chi^{2} / \mathrm{df}$ was less than three; the goodness of fit index, normed fit index, and comparative fit index were all above 0.90 , and the root mean-squared error of approximation was less than 0.08. For the structural model, 2000 bias-corrected samples were extracted to calculate the path coefficients and their significance, and the total, direct, and indirect effects of the variables were calculated. A P-value (twotailed) less than 0.05 was considered to have significant

Table I Convergent Validity and Reliability Analysis

\begin{tabular}{|l|c|c|c|c|c|}
\hline Constructs & Items & Factor Loadings & CR(>0.7) & AVE(>0.5) & Cronbach's $\alpha$ \\
\hline PE & PEI & 0.877 & 0.906 & 0.828 & 0.840 \\
& PE2 & 0.942 & 0.844 & 0.731 & 0.746 \\
\hline EE & EEI & 0.831 & & 0.759 & 0.778 \\
& EE2 & 0.878 & 0.863 & 0.715 & 0.791 \\
& SII & 0.881 & & \\
\end{tabular}

Abbreviations: PE, performance expectancy; $\mathrm{EE}$, effort expectancy; SI, social influence; $\mathrm{FC}$, facilitating condition. 
Table 2 Discriminant Validity

\begin{tabular}{|l|l|l|l|l|}
\hline Square Root of AVE & PE & EE & SI & FC \\
\hline PE & 0.910 & & & \\
EE & 0.984 & 0.855 & & \\
SI & 0.930 & 0.965 & $0.87 I$ & \\
FC & 0.926 & 0.960 & 0.908 & 0.846 \\
\hline
\end{tabular}

Abbreviations: $\mathrm{PE}$, performance expectancy; $\mathrm{EE}$, effort expectancy; $\mathrm{SI}$, social influence; FC, facilitating condition.

effects. $\mathrm{R}^{2}$ was used to represent the explanatory degree of the independent variables with respect to the dependent variables.

\section{Results}

\section{Demographic Characteristics of MSM}

In our study, the average age of MSM was 29.95 years (ranging from 17 to 54). Of them, 58.18\% were from urban areas, $98.20 \%$ were Han, only $8.11 \%$ had not attended high school, $71.17 \%$ had jobs, $24.32 \%$ were students, $81.08 \%$ were unmarried, and $66.97 \%$ had a monthly salary less than 5000 yuan.

\section{Measurement Model Testing}

The composite reliability, Cronbach alpha, and AVE of each construct are shown in Table 1. They were all greater than their recommended values, which indicates good reliability and convergent validity. As shown in Table 2, the correlation coefficient between any pair of dimensions was greater than the AVE, because of which the discriminant validity of each dimension needed to be further verified. Model comparison was used to assess the discriminant validity of each dimension in this study. Model 2 was established by setting the standardized correlation coefficient of each dimension to one, and the P-value of the model comparison was less than 0.05 , which means that the discriminant validity of the measurement model was acceptable Table 3 shows the fitting index of the measurement model. All fitting index values were within the reference range except for the root mean square of the asymptotic residual, which indicates that the collected data fitted the measurement model well.

\section{Structural Model Testing}

Figure 3 and Table 4 show that two of the six hypotheses (H2 and H5) were rejected, and the standardized regression weights of all other links were significant $(\mathrm{P}<0.05)$. Performance expectancy was found to play a mediating role in the relationship between social influence and behavior intention. The direct, indirect, and total effects of social influence on behavior intention are shown in Table 5. Performance expectancy, social influence, and perceived privacy risk explained $40.9 \%$ of the variance in behavior intention. Social influence had the greatest impact of these three factors $(\beta=0.360, \mathrm{P}<0.001)$, followed by performance expectancy $(\beta=0.331, \mathrm{P}<$ 0.001 ), and perceived privacy risk had a negative impact on behavior intention $(\beta=-0.151, P=0.040)$. In addition, social influence had an indirect effect on behavior intention $(\beta=0.182, P=0.003)$ and performance expectancy played a mediating role in this indirect effect. Social influence explained $30.3 \%$ of the variation in performance expectancy $(\beta=0.550, \mathrm{P}=0.001)$.

\section{Discussion}

\section{Social Influence, Performance Expectancy, and Perceived Privacy Risk Can Affect the Intention of MSM to Use the IRS}

Social influence and performance expectancy were the most important determinants of the behavior intention of MSM to use the IRS. Some studies have also pointed out the importance of social influence and performance expectancy in this context. ${ }^{27,29,32}$ Performance expectancy refers to the benefits that users expect the new system to bring. MSM will be more willing to use it if they believe that they can benefit from the system. Social influence is the degree of support for using the system from those who are closely related to the users. MSM are afraid of being discriminated against. Therefore, if they can receive support from relatives and friends, this can inspire them. At the same time, traditional socio-cultural values and norms of behavior related to sexuality determine behaviors and

Table 3 Fit Indices

\begin{tabular}{|l|c|c|c|c|c|}
\hline Fit Indexes & $\chi^{2}$ /df & GFI & NFI & CFI & RMSEA \\
\hline Measurement model & 2.625 & 0.922 & 0.917 & 0.946 & 0.122 \\
Recommended value & $<3$ & $>0.9$ & $>0.9$ & $>0.9$ & $<0.08$ \\
\hline
\end{tabular}

Abbreviations: GFI, goodness of fit index; NFI, normed fit index; CFI, comparative fit index; RMSEA, root mean-squared error of approximation. 


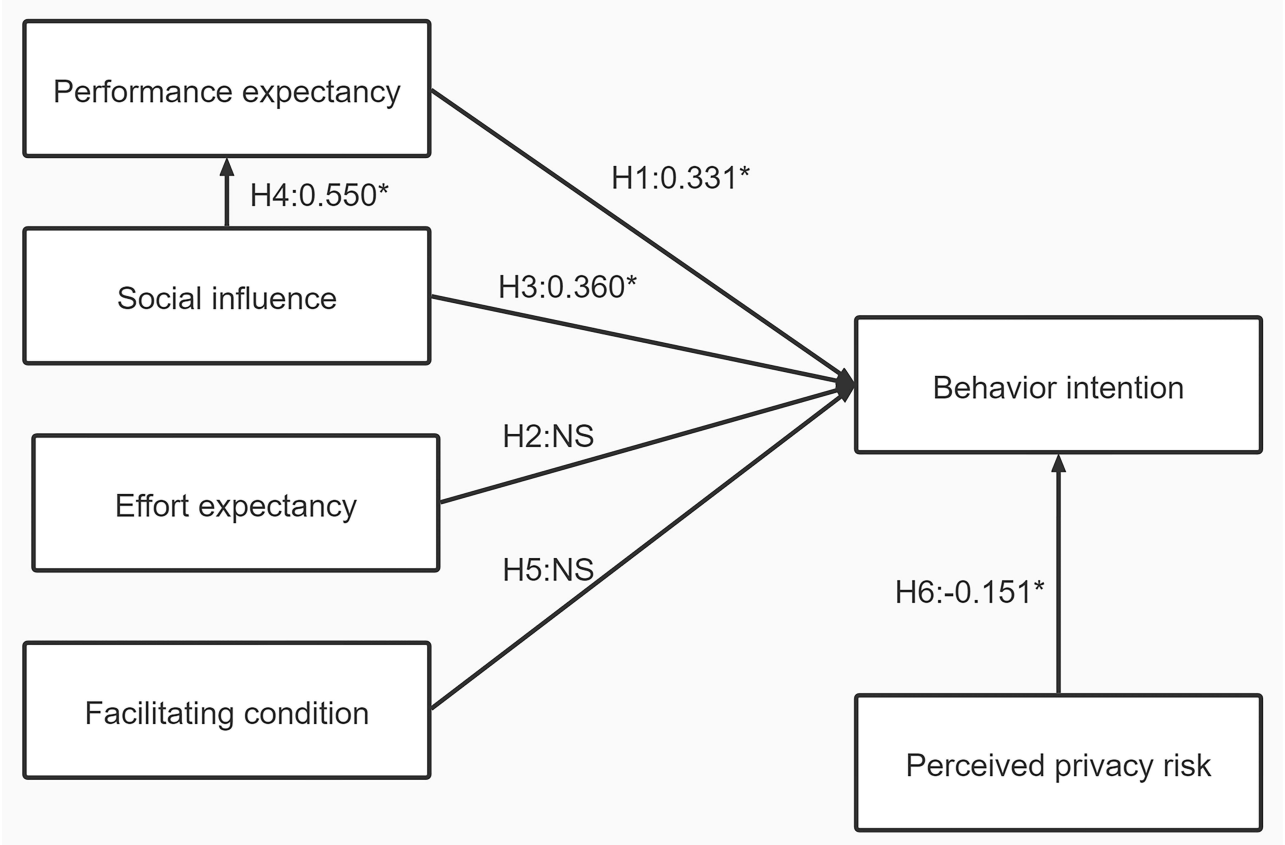

Figure 3 Standardized regression weights of research model: *:P $\leq 0.05$, NS:P>0.05.

characteristics that are considered acceptable. ${ }^{33}$ If individuals or groups deviate from these accepted behaviors and characteristics, such as by participating in homosexual relationships, they risk being stigmatized and marginalized. ${ }^{34}$ Related studies in Tanzania have noted that social stigma seriously hinders the intention and behavior of MSM to access HIV-related services. ${ }^{35,36}$ Therefore, improving the social acceptance of MSM is an important factor that affects their willingness to use the IRS.

With advances in the Internet, people have come to attach growing importance to their personal privacy, ${ }^{37}$ especially MSM. As Rudolph et al found, ${ }^{19}$ perceived privacy risk has a negative impact on the willingness of

Table 4 Standardized Regression Weights Between the Model Variables

\begin{tabular}{|l|c|c|c|}
\hline Path (Support) & $\boldsymbol{\beta}$ & t-value & P-value \\
\hline $\mathrm{HI}: \mathrm{PE} \rightarrow \mathrm{BI}(\mathrm{Yes})$ & $0.33 \mathrm{I}$ & $3.77 \mathrm{I}$ & $<0.00 \mathrm{I}$ \\
$\mathrm{H} 2: \mathrm{EE} \rightarrow \mathrm{BI}(\mathrm{No})$ & 0.105 & 0.872 & 0.383 \\
$\mathrm{H} 3: \mathrm{SI} \rightarrow \mathrm{BI}($ Yes) & 0.360 & 3.719 & $<0.00 \mathrm{I}$ \\
$\mathrm{H} 4: \mathrm{SI} \rightarrow \mathrm{PE}($ Yes) & 0.550 & 5.448 & $<0.00 \mathrm{I}$ \\
$\mathrm{H} 5: \mathrm{FC} \rightarrow \mathrm{BI}(\mathrm{No})$ & 0.069 & 0.863 & 0.388 \\
$\mathrm{H} 6: \mathrm{PPR} \rightarrow \mathrm{BI}($ Yes) & $-0.15 \mathrm{I}$ & -2.055 & 0.040 \\
\hline
\end{tabular}

Abbreviations: $\mathrm{PE}$, performance expectancy; EE, effort expectancy; SI, social influence; FC, facilitating condition; $\mathrm{Bl}$, behavior intention; PPR, perceived privacy risk.
MSM using new techniques. We also found that many MSM were unwilling to reveal their real names, showing a strong sense of personal privacy. Therefore, it is important to show that the IRS preserves their privacy, for which it is necessary to improve its capability in this regard.

\section{Social Influences Affect the Performance Expectancy of IRS}

Products recommended by doctors were considered reliable by the subjects, and this is consistent with previous research. ${ }^{38}$ Healthcare providers are a critical source of HIV prevention, and the reception of prevention services by MSM is influenced by their healthcare providers. As well as providing PrEP and IRS to MSM, explaining the

Table 5 Mediating Effect

\begin{tabular}{|l|c|c|c|c|c|}
\hline Variable & \multirow{2}{*}{ Effect } & \multicolumn{2}{|c|}{$\begin{array}{c}\text { Performance } \\
\text { Expectancy }\end{array}$} & \multicolumn{2}{c|}{$\begin{array}{c}\text { Behavior } \\
\text { Intention }\end{array}$} \\
\cline { 3 - 6 } & & $\boldsymbol{\beta}$ & P-value & $\boldsymbol{\beta}$ & P-value \\
\hline Social influence & Direct & 0.550 & 0.001 & 0.360 & 0.007 \\
\cline { 2 - 6 } & Indirect & & & 0.182 & 0.003 \\
\cline { 2 - 6 } & Total & 0.550 & 0.001 & 0.543 & 0.001 \\
\hline
\end{tabular}

Abbreviations: PE, performance expectancy; $\mathrm{Sl}$, social influence; $\mathrm{Bl}$, behavior intention. 
role of IRS is an important step in recommending its use. It is equally important to enhance the capacity of healthcare providers. $^{39,40}$

\section{Effort Expectation and Facilitating Conditions Do Not Influence Behavior Intention}

We found that effort expectation and facilitating conditions did not affect behavior intention, but were important in the UTAUT. Effort expectation refers to the effort it takes for a user to use the system, and facilitating condition refers to the ease with which resources are available to use the system. We think that this result might be related to the surveyed population. In a number of studies on the use of home telehealth services by the elderly, ${ }^{41,42}$ effort expectation has been found to have a strong positive impact. However, the population surveyed for the questionnaire in this study was generally young (the oldest subject was only 54 years old), and $91.89 \%$ of the MSM had had senior-level high school education or higher; they would have had no difficulty in using the Internet or mobile phones. The IRS and PrEP were provided to them for free, although this system can be realized only through WeChat, which is the most widely used online social media network in China. ${ }^{43}$ There was thus no difficulty in using WeChat.

\section{Deficiencies and Prospects}

This study did not record in detail the actual use of the IRS by the subjects. Factors influencing the actual use of system were thus not explored. Although behavior intention is considered to be a key factor affecting actual use, some differences occur between actual use and behavior intention to use. $^{44}$

Over a long period of time using the system, the users' behavior intention varies from high to low. A study by Himelhoch et al showed that owing to the lack of continuous innovation in the relevant apps, patients suffered from burnout, and the frequency of app use decreased by about $25 \%$ in their three-month experiment. ${ }^{45}$ Therefore, a cross-sectional survey of factors influencing behavior intention may not be sufficient, and further longitudinal surveys are needed to observe this effect.

This model only explained $40.9 \%$ of the variation in behavior intention, indicating that many other factors affect the intention among MSM to use IRS. Future studies should explore such possible structures, such as the impact of task technology matching. ${ }^{27}$

\section{Conclusion}

Social influence and performance expectancy were found to be the most important determinants of the choice of MSM to use the IRS. Therefore, it is important to eliminate discrimination against MSM, and the development of such a system must take into account its usefulness. It is equally important to explain the role of the IRS when recommending it to MSM. Perceived privacy risk also influences behavior intention, because of which it is necessary to improve the system's privacy protection capability. Moreover, it is necessary to provide clinical evidence for the effectiveness of the IRS to promote its use.

\section{Ethical Approval and Consent to Participate}

The study followed the Helsinki Declaration, and was approved by The Ethics Committee of Chongqing Medical University and the Ethics Committee of Chongqing Medical University. Formal consent was obtained from all participants before we used their information, and this paper does not contain any feature that can be used to identify the subjects. All participants all provided their written and informed consent.

\section{Acknowledgment}

We thank all participants and investigators for their help.

\section{Funding}

This work was supported by the National Key Project for Infectious Diseases of the Ministry of Science and Technology of China (2012ZX10001007-007 and 2018ZX10721102-005).

\section{Disclosure}

The authors have no conflicts of interest to report regarding the publication of this work.

\section{References}

1. Liu J, Deng R, Lin B, et al. Risk management on pre-exposure prophylaxis adherence of men who have sex with multiple men: a Multicenter Prospective Cohort Study. Risk Manag Healthc Policy. 2021;14:1749-1761. doi:10.2147/RMHP.S295114

2. Qiao YC, Xu Y, Jiang DX, et al. Epidemiological analyses of regional and age differences of HIV/AIDS prevalence in China, 2004-2016. Int J Infect Dis. 2019;81:215-220. doi:10.1016/j.ijid.2019.02.016

3. Tang Q, Lu H. HIV/AIDS responses in China should focus on the impact of global integration. Biosci Trends. 2018;12(5):507-509. doi:10.5582/bst.2018.01269 
4. Qin Q, Guo W, Tang W, et al. Spatial analysis of the human immunodeficiency virus epidemic among men who have sex with men in China, 2006-2015. Clin Infect Dis. 2017;64(7):956-963. doi:10.1093/cid/cix031

5. Wu D, Tang W, Lu H, et al. Leading by example: web-based sexual health influencers among men who have sex with men have higher HIV and syphilis testing rates in China. J Med Internet Res. 2019;21 (1):e10171. doi:10.2196/10171

6. Centers for Disease Control and Prevention. National Gay Men's HIV/AIDS Awareness Day-September 27, 2019. MMWR Morb Mortal Wkly Rep. 2019;68(37):801. doi:10.15585/mmwr.mm6837a1

7. Huang MB, Ye L, Liang BY, et al. Characterizing the HIV/AIDS Epidemic in the United States and China. Int J Environ Res Public Health. 2015;13(2):30. doi:10.3390/ijerph13010030

8. Guo Z, Xiao D, Xu S, He K. Analysis and forecast of the HIV/AIDS epidemic in Mainland China, 1985-2016. J Public Health. 2020;42 (4):e458-e467. doi:10.1093/pubmed/fdz116

9. Zhong X, Zhong X, Peng B, Zhang Y, Huang A. Acceptability and influencing factors of pre-exposure prophylaxis among men who have sex with men in Chongqing. J Chongqing Med Univ. 2013;38 (4):389-394

10. Spinner CD, Boesecke C, Zink A, et al. HIV pre-exposure prophylaxis (PrEP): a review of current knowledge of oral systemic HIV PrEP in humans. Infection. 2016;44(2):151-158. doi:10.1007/ s15010-015-0850-2

11. Wu D, Tao H, Dai J, Liang H, Huang A, Zhong X. Study on pre-exposure prophylaxis regimens among men who have sex with men: a Prospective Cohort Study. Int J Environ Res Public Health 2019;16(24):4996. doi:10.3390/ijerph16244996

12. Grant RM, Lama JR, Anderson PL, et al. Preexposure Chemoprophylaxis for HIV Prevention in Men Who Have Sex with Men. $N$ Engl J Med. 2010;363(27):2587-2599. doi:10.1056/ NEJMoa1011205

13. Smith DK, Koenig LJ, Martin M, et al. Preexposure prophylaxis for the prevention of HIV infection in the United States-2014: a clinical practice guideline. Korean J Ophthalmol. 2014;27(4):282-287.

14. World Health Organization. Guideline on When to Start Antiretroviral Therapy and on Pre-Exposure Prophylaxis for HIV. Geneva Switzerland: World Health Organization; 2015.

15. Li J, Wang L, Qiu J. Design and research of an intelligent medicine box. J Phys Conf Ser. 2021;1939:1.

16. Yin Y, Wei W, Wang Y, et al. Theory and practice analysis of intelligent medicine box. Electron J General Stomatol. 2019;6 (18):37-38

17. Brown W, Giguere R, Sheinfil A, et al. Challenges and solutions implementing an SMS text message-based survey CASI and adherence reminders in an international biomedical HIV PrEP study (MTN 017). $J$ Biomed Inform. 2018;80:78-86. doi:10.1016/j.jbi.2018.02.018

18. Liu AY, Laborde ND, Coleman K, et al. DOT diary: developing a novel mobile app using artificial intelligence and an electronic sexual diary to measure and support prep adherence among young men who have sex with men. AIDS Behav. 2021;25(4):1001-1012. doi:10.1007/s10461-020-03054-2

19. Rudolph AE, Young AM, Havens JR. Privacy, confidentiality, and safety considerations for conducting geographic momentary assessment studies among persons who use drugs and men who have sex with men. J Urban Health. 2020;97(2):306-316. doi:10.1007/ s11524-018-0315-x

20. Diaz JE, Schrimshaw EW, H V T, Nandi V, Koblin BA, Frye V. Acculturation as a Moderator of HIV Risk Behavior Correlates Among Latino Men Who Have Sex with Men. Arch Sex Behav. 2020;49(6):2029-2043. doi:10.1007/s10508-019-01604-x

21. Isano S, Wong R, Logan J, El-Halabi S, El-Khatib Z. Barriers to post exposure prophylaxis use among men who have sex with men in sub-Saharan Africa: an online cross-sectional survey. Prev Med Rep. 2020;1:19.
22. Öhman J, Larsson M, Kashiha J, Agardh A. 'Fighting an uphill battle': a qualitative study of the challenges encountered by pharmacy workers when providing services to men who have sex with men in Dar Es Salaam, Tanzania. Glob Health Action. 2020;13 (1):1770985. doi:10.1080/16549716.2020.1770985

23. Sun S, Pachankis JE, Li X, Operario D. Addressing Minority Stress and Mental Health among Men Who Have Sex with Men (MSM) in China. Curr HIV/AIDS Rep. 2020;17(1):35-62. doi:10.1007/s11904019-00479-w

24. Zhao Y, Zhang L, Zhang H, et al. HIV testing and preventive services accessibility among men who have sex with men at high risk of HIV infection in Beijing, China. Medicine. 2015;94(6):e534. doi:10.1097/ MD.0000000000000534

25. Liu JX, Choi K. Experiences of social discrimination among men who have sex with men in Shanghai, China. AIDS Behav. 2006;10 (4Suppl):S25-S33. doi:10.1007/s10461-006-9123-5

26. Ammenwerth E. Technology Acceptance Models in Health Informatics: TAM and UTAUT. Stud Health Technol Inform. 2019;263:64-71. doi:10.3233/SHTI190111

27. Hoque R, Sorwar G. Understanding factors influencing the adoption of mHealth by the elderly: an extension of the UTAUT model. Int $J$ Med Inform. 2017;101(May):75-84. doi:10.1016/j. ijmedinf.2017.02.002

28. Wang H, Tao D, Yu N, Qu X. Understanding consumer acceptance of healthcare wearable devices: an integrated model of UTAUT and TTF. Int J Med Inform. 2020;139:104156.

29. Zhang Y, Liu C, Luo S, et al. Factors influencing patients' intentions to use diabetes management apps based on an extended unified theory of acceptance and use of technology model: web-based survey. JMIR Mhealth Uhealth. 2019;21(8):e15023.

30. Or CK, Karsh BT, Severtson DJ, Burke LJ, Brown RL, Brennan PF. Factors affecting home care patients' acceptance of a web-based interactive self-management technology. $J$ Am Med Inform Assoc. 2011;18(1):51-59. doi:10.1136/jamia.2010.007336

31. Leguina A. A primer on partial least squares structural equation modeling (PLS-SEM). Int J Res Method Educ. 2015;38(2):220-221. doi:10.1080/1743727X.2015.1005806

32. Apolinário-Hagen J, Menzel M, Hennemann S, Salewski C. Acceptance of Mobile Health Apps for Disease Management Among People With Multiple Sclerosis: web-Based Survey Study. JMIR Formative Res. 2018;2:2. doi:10.2196/11977

33. Link BG, Phelan JC. Conceptualizing Stigma. Annu Rev Sociol. 2001;27(6):363-385. doi:10.1146/annurev.soc.27.1.363

34. Dudley JR. Confronting stigma within the services system. Soc Work. 2000;1(5):449-455. doi:10.1093/sw/45.5.449

35. Magesa DJ, Mtui LJ, Abdul M, et al. Barriers to men who have sex with men attending HIV related health services in Dar Es Salaam, Tanzania. Tanzan J Health Res. 2014;16(2):118-126. doi:10.4314/ thrb.v16i2.8

36. Ross MW, Larsson M, Nyoni JE, Agardh A. Prevalence of STI symptoms and high levels of stigma in STI healthcare among men who have sex with men in Dar Es Salaam, Tanzania: a respondent-driven sampling study. Int $J$ STD AIDS. 2017;28 (9):925-928. doi:10.1177/0956462416683625

37. Mahmoodi J, Čurdová J, Henking C, et al. Internet users' valuation of enhanced data protection on social media: which aspects of privacy are worth the most? Front Psychol;2018. 9. doi:10.3389/ fpsyg.2018.00009

38. Zhang Y, Li X, Luo S, et al. Use, perspectives, and attitudes regarding diabetes management mobile apps among diabetes patients and diabetologists in china: national web-based survey. JMIR Mhealth Uhealth. 2019;7(2):e12658. doi:10.2196/12658

39. Moore E, Kelly SG, Alexander L, et al. Tennessee Healthcare Provider Practices, Attitudes, and Knowledge Around HIV Pre-Exposure Prophylaxis. J Prim Care Community Health. 2020;11:2150132720984416. doi:10.1177/2150132720984416 
40. Wilson K, Bleasdale J, Przybyla SM. Provider-Patient Communication on Pre-Exposure Prophylaxis (Prep) for HIV Prevention: an Exploration of Healthcare Provider Challenges[published online ahead of print, 2020 Jul 7]. Health Commun. 2020;1;1-10.

41. Cimperman M, Brencic MM, Trkman P. Analyzing older users' home telehealth services acceptance behavior-applying an Extended UTAUT model. Int $J$ Med Inform. 2016;90(Jun):22-31. doi:10.1016/j.ijmedinf.2016.03.002

42. de Veer AJ, Peeters JM, Brabers AE, Schellevis FG, Rademakers JJ, Francke AL. Determinants of the intention to use e-Health by community dwelling older people. BMC Health Serv Res. 2015;15:103. doi:10.1186/s12913-015-0765-8
43. Luan H, Wang M, Sokol RL, Wu S, Victor BG, Perron BE. A scoping review of WeChat to facilitate professional healthcare education in Mainland China. Med Educ Online. 2020;25(1):1782594. doi:10.1080/10872981.2020.1782594

44. Bhattacherjee A, Sanford C. The intention-behaviour gap in technology usage: the moderating role of attitude strength. Behav Inf Technol. 2009;28(4):389-401. doi:10.1080/01449290802121230

45. Himelhoch S, Kreyenbuhl J, Palmer-Bacon J, Chu M, Brown C, Potts W. Pilot feasibility study of Heart2HAART: a smartphone application to assist with adherence among substance users living with HIV. AIDS Care. 2017;29(7):898-904. doi:10.1080/ 09540121.2016 .1259454
Risk Management and Healthcare Policy

\section{Publish your work in this journal}

Risk Management and Healthcare Policy is an international, peerreviewed, open access journal focusing on all aspects of public health, policy, and preventative measures to promote good health and improve morbidity and mortality in the population. The journal welcomes submitted papers covering original research, basic science, clinical \& epidemiological studies, reviews and evaluations,

\section{Dovepress}

guidelines, expert opinion and commentary, case reports and extended reports. The manuscript management system is completely online and includes a very quick and fair peer-review system, which is all easy to use. Visit http://www.dovepress.com/testimonials.php to read real quotes from published authors. 